\title{
The Role of Bromodomain and Extraterminal Motif (BET) Proteins in Chromatin Structure
}

\author{
Sarah C. Hsu ${ }^{1}$ and Gerd A. Blobel ${ }^{1,2}$ \\ ${ }^{1}$ Perelman School of Medicine, University of Pennsylvania, Philadelphia, Pennsylvania 19104 \\ ${ }^{2}$ Division of Hematology, Children's Hospital of Philadelphia, Philadelphia, Pennsylvania 19104 \\ Correspondence: blobel@email.chop.edu
}

\begin{abstract}
Bromodomain and extraterminal motif(BET) proteins have been widely investigated for their roles in gene regulation and their potential as therapeutic targets in cancer. Pharmacologic BET inhibitors target the conserved bromodomain-acetyllysine interaction and do not distinguish between BRD2, BRD3, and BRD4. Thus, comparatively little is known regarding the distinct roles played by individual family members, as well as the underlying mechanisms that drive the transcriptional effects of BET inhibitors. Here we review studies regarding the contributions of BET proteins to genome structure and function, including recent work identifying a role for BRD2 as a component of functional and physical chromatin domain boundaries. We also discuss directions of future studies aimed at providing insights into broader architectural functions of BET proteins and their roles in chromatin domain boundary formation.
\end{abstract}

Bromodomain and extraterminal motif (BET) proteins bind chromatin and play critical roles in transcription. The BET family consists of BRD2, BRD3, and BRD4, which are broadly expressed across tissues, as well as BRDT, which is predominantly present in the testes (Shang et al. 2004). BET proteins are characterized by their conserved domain structure, which consists of two aminoterminal bromodomains that bind acetylated lysine residues on histones and other proteins, as well as an extraterminal domain that mediates further protein-protein interactions (for review, see Belkina and Denis 2012). BET proteins are generally considered to be chromatin "readers" that translate the chromatin state into gene activity by recruiting transcriptional regulatory complexes to their binding sites. BRD4 in particular has been widely investigated as a transcriptional activator. BRD4 is present in protein complexes such as PTEF-b (Jang et al. 2005; Yang et al. 2005; Bisgrove et al. 2007), which phosphorylates control elements of the elongation machinery and RNA polymerase II (Pol II) to stimulate productive transcription elongation. The functions of BRD2 and BRD3 are less well-characterized, although BRD2 has also been associated with gene activation as a member of E2F-containing complexes (Denis et al. 2000; Sinha et al. 2005).

The advent of pharmacologic inhibitors of the BET bromodomain-acetyllysine interaction has revealed that targeting BET proteins has therapeutic potential in a wide variety of disorders including cancer (Filippakopoulos et al. 2010; Dawson et al. 2011; Delmore et al. 2011; Zuber et al. 2011; Shi and Vakoc 2014), heart failure (Anand et al. 2013), and inflammatory conditions (Nicodeme et al. 2011). Interestingly, despite the ubiquitous expression of BET proteins and the presence of one or more at essentially all active genes (Anders et al. 2013),
BET inhibition does not result in global transcriptional down-regulation but rather has gene-specific effects that seem to depend largely on cellular context (for review, see Shi and Vakoc 2014). BRD2, BRD3, and BRD4 can bind to overlapping as well as distinct regions of the genome (Anders et al. 2013; Asangani et al. 2015; Stonestrom et al. 2015), yet whether they regulate different genes or perform separate functions has yet to be clearly delineated. This point is also relevant when interpreting the biological functions of BET inhibitors, most of which target all members of the BET family.

Many questions remain regarding the mechanisms by which BET proteins regulate transcription. In particular, what explains the gene selectivity of BET inhibitors? What distinguishes the roles of BRD2, BRD3, and BRD4? Do they function at distinct stages of transcription? Which BET proteins account for the phenotype of BET inhibition in a particular context? Here we discuss a role for BET proteins in the maintenance of chromatin structure, from the local chromatin environment to largescale 3D genome architecture, and how architectural functions of BET proteins may influence gene regulation.

\section{BET PROTEINS ARE LINKED TO THE MAINTENANCE OF LARGE-SCALE NUCLEAR STRUCTURE}

BET proteins are most widely known for their ability to "read" or "interpret" acetylated chromatin. Most work regarding BET proteins has focused on their roles as transcriptional activators; however, a number of studies have also highlighted functions of BET proteins important for large-scale chromatin structure. Specifically, either deple-

(C) 2017 Hsu and Blobel. This article is distributed under the terms of the Creative Commons Attribution-NonCommercial License, which permits reuse and redistribution, except for commercial purposes, provided that the original author and source are credited. 
tion of BRD4 or disruption of BRD4 binding using a dominant-negative form consisting of the tandem bromodomains leads to chromatin decondensation and fragmentation as measured by MNase and imaging techniques (Wang et al. 2012). Of note, given the conserved structure of the bromodomains between family members, it is possible that such a method of inhibition could also interfere with BRD2 or BRD3 function. Regions in the carboxyl terminus of BRD4 are important for maintaining chromatin structure (Wang et al. 2012), suggesting that BRD4 may recruit additional proteins to perform this function. Other studies have reported a role for BRD4 in chromatin compaction, yet have described conflicting results. Specifically, recruitment (rather than disruption) ofBRD4 to an artificial locus using a LacI fusion system resulted in expansion of the region in imaging studies (Zhao et al. 2011), suggesting that BRD4 is linked to chromatin decompaction. Overexpression of BRD4 in HeLa cells resulted in increased nuclear volume, and BRD4 levels were also associated with increased sensitivity of chromatin to MNase digestion in vitro (Devaiah et al. 2016), suggesting that BRD4's regulation of global chromatin structure is likely complex and context-specific.

BRDT, another member of the BET family that is expressed primarily in the testes, plays a role in chromatin structure during spermatogenesis. Spermatogenesis is a dynamic process during which chromatin organization and cellular morphology undergo dramatic changes - namely, nuclear compaction and histone hyperacetylation and replacement with transition proteins and protamines (Rajender et al. 2011). Ectopic expression of BRDT in non-germ cells resulted in global changes in chromatin organization, including inducing the formation of condensed nuclear foci in a manner requiring the bromodomains (Pivot-Pajot et al. 2003). Disruption of Brdt in mice results in disrupted nuclear morphology in sperm cells as revealed by electron microscopy, as well as fragmentation of the chromocenter, a structure formed by pericentromeric heterochromatin (Shang et al. 2007; Berkovits and Wolgemuth 2011). These observations suggest that BRDT has critical roles in the maintenance of chromatin structure. Notably, in spermatids BRD4 is enriched in a unique ringlike structure at the base of the acrosome, and it has been speculated that this ring might contain a slightly smaller spermatid-specific BRD4 isoform that binds to acetylated proteins to promote chromatin compaction and reorganization during spermatid maturation (Bryant et al. 2015).

In addition, a number of studies have detected persistent BET binding to chromatin during mitosis, a phase of the cell cycle associated with extreme changes in $3 \mathrm{D}$ chromatin structure (Naumova et al. 2013). BRD4 (Dey et al. 2000, 2009; Zhao et al. 2011), BRD2 (Kanno et al. 2004), and BRD3 (Garcia-Gutierrez et al. 2012) have been shown to remain bound to mitotic chromosomes by various methods including chromatin immunoprecipitation and imaging studies. Whether or how BET proteins influence mitotic chromosome organization has yet to be tested.

Although manipulation of BET proteins results in clear defects in chromatin organization in the nucleus, the mechanism by which they contribute to chromatin architecture remains to be elucidated. In particular, do BET proteins themselves play a structural or architectural role? Alternatively, are the structural changes observed secondary to transcriptional disruption? How do effects on chromatin structure relate to gene regulation by BET proteins? Observations regarding these questions are discussed in the sections that follow.

\section{BET PROTEINS MODULATE THE LOCAL CHROMATIN ENVIRONMENT}

One mechanism by which BET proteins may control chromatin organization is through effects on the surrounding chromatin environment. BET proteins bind to acetylated residues on histones and other proteins, and a number of lines of evidence suggest that BETs can either directly or indirectly influence histone modifications and DNA accessibility. Proteomics studies have shown that BETs reside in nuclear complexes with chromatin-modifying enzymes (Dawson et al. 2011; Rahman et al. 2011) such as histone methyltransferases and chromatin remodeling machinery. BRD4 associates with the H3K36 methyltransferase NSD3 (Rahman et al. 2011), and BRD4 depletion results in a reduction in $\mathrm{H} 3 \mathrm{~K} 36 \mathrm{me} 3$ at specific loci. In addition, a short version of NSD3 lacking catalytic activity connects BRD4 to CHD8, an ATP-dependent chromatin-remodeling enzyme (Shen et al. 2015), indicating that BET proteins can indirectly impact the local structure of the genes they regulate. BRD2 and BRD3 associate with hyperacetylated nucleosomes and assist Pol II transcription elongation in vitro, suggesting they have histone chaperone activity (LeRoy et al. 2008).

Recent reports have suggested that BRD4 also has inherent activity as a protein kinase (Devaiah et al. 2012) and histone acetyltransferase (Devaiah et al. 2016). The latter has been proposed to deposit H3K122ac, a modification on the surface of the globular histone domain. This study showed that BRD4 was associated with chromatin decompaction, nucleosome eviction in vitro, and decreased nucleosome occupancy in vivo. It should be noted, however, that although H3K122ac stimulates transcription, it did not significantly impact chromatin compaction in in vitro chromatin assembly assays in other reports (Tropberger et al. 2013), suggesting that BRD4's effects on chromatin compaction may be propagated through multiple mechanisms.

BRD4, and likely BRD3, also plays a role in defective chromatin regulation in the setting of malignancy. NUT midline carcinoma, a rare squamous cell cancer, is driven by translocations generating oncogenic fusion proteins that bring BRD3 or BRD4 into close association with the protein NUT. BRD4-NUT fusions form foci in the nuclei of NUT midline carcinoma cells and can generate large, hyperacetylated "megadomains" that are associated with broad transcriptional activation of the genes they contain (Alekseyenko et al. 2015), likely through a mechanism involving the p300 acetyltransferase (Alekseyenko et al. 2017). Interestingly these megadomains appear to 
initiate from active enhancers and are largely cell typespecific, indicating that the impact of BET proteins on chromatin structure may be strongly influenced by the existing cellular transcriptional program.

Thus, one mechanism by which BETs alter chromatin structure may be through modulation of histone modifications that govern the local chromatin environment. However, whether such changes are directly linked to gene expression awaits further study. In particular, can the transcriptional effects of BET inhibitors be rescued by restoring the binding of BET-associated histone modifiers? Targeted tethering of BET proteins or their downstream cofactors to specific genomic loci may provide insight into establishing a causal relationship. In addition, the effects of BET disruption on surrounding histone modifications may be secondary to changes in the transcriptional state of a given gene. Using systems such as the auxin-inducible or FKBP-derived degrons to rapidly and specifically degrade $\mathrm{BRD} 2, \mathrm{BRD} 3$, or BRD4 has the potential to provide insight into the direct effects of BET proteins on local chromatin structure.

\section{BETS AS INSULATOR/ARCHITECTURAL PROTEINS}

Early work in yeast provided evidence that BETs may play a role in chromatin boundary integrity or barrier function. Yeast have two BET homologs, Bdf1 and Bdf2, that share domain structure similar to mammalian BETs (Wu and Chiang 2007). Microarray analysis of gene expression in yeast strains with either deletion of $B D F 1$ or mutations in Bdfl that abrogate binding to acetylated residues revealed that nearly one-third of down-regulated genes are within $100 \mathrm{~kb}$ of telomeres (Ladurner et al. 2003). The authors showed that this occurs through a mechanism involving competitive binding between Bdf1 and the SIR silencing complex, with loss of acetyl-histone binding by Bdf1 allowing the expansion of telomere-proximal binding of Sir3 with concomitant reduction of H4 acetylation. This mechanism is further supported by the observation that yeast lacking SIR3 have the opposite phenotype, with increased subtelomeric binding of Bdfl. Thus in yeast, Bdf1 performs a type of barrier function to prevent the inappropriate spread of heterochromatin. Whether BET inhibition similarly allows the spread of heterochromatin or the blurring of heterochromatin-euchromatin boundaries in mammalian cells has not been explored in detail. Interestingly, this model implies that the overall levels of BET proteins within the cell must be carefully titrated to ensure an appropriate balance between the active and repressed chromatin state.

A barrier function for BRDT was also suggested by studies of spermatogenesis, where loss of the first bromodomain of BRDT in mice led to increased levels of chromatin-associated HP $1 \alpha$ in the testes, suggesting an overall increase in heterochromatin (Berkovits and Wolgemuth 2011). By immunofluorescence imaging, BRDT and the mammalian sirtuin SIRT1 were localized adjacent to the heterochromatic chromocenter, suggesting a similar mechanism for BRDT in preventing the spread of heterochromatin as described above for yeast.

In addition to barrier functions, BET proteins associate with insulator proteins in multiple organisms. Drosophila have a single BET homolog, $\mathrm{F}(\mathrm{s}) 1 \mathrm{~h}$, which is expressed in two isoforms - F(s) $1 \mathrm{~h}-\mathrm{S}$ (short) and F(s)1h-L (long) that contains an additional extended carboxy-terminal domain. Genome-wide analysis of differential binding by these two isoforms revealed that $\mathrm{F}(\mathrm{s}) \mathrm{h}-\mathrm{h}$ is present at active enhancers and promoters, while $\mathrm{F}(\mathrm{s}) 1-\mathrm{h}-\mathrm{L}$ additionally binds to sites occupied by Drosophila insulator proteins (Kellner et al. 2013). Fs(1)h-L interacts with the insulator proteins GAF, $\mathrm{Su}(\mathrm{Hw})$, Mod(mdg4), and CP190 in co-immunoprecipitation experiments. The ability of insulator proteins to form homo- and heterotypic interactions is thought to enable chromosome folding in a manner that constrains enhancer-promoter contacts to shield genes from inappropriate regulation (Schwartz and Cavalli 2017).

In mammalian cells we recently observed that the BET protein BRD2 occupies sites bound by the architectural/ insulator protein CTCF in erythroid cells (Hsu et al. 2017). This is in line with findings from another recent study showing significant overlap between BRD2 and CTCF binding in Th17 cells (Cheung et al. 2017) and in the Kaposi's sarcoma-associated herpesvirus genome (Chen et al. 2017), indicating that the relationship between BRD2 and CTCF is a widespread phenomenon. We observed that BRD3 also binds to CTCF sites, consistent with previous work from our laboratory demonstrating partial functional redundancy between BRD2 and BRD3 in erythroid maturation (Stonestrom et al. 2015). BRD4 did not similarly localize to CTCF sites in either erythroid (Hsu et al. 2017) or Th17 (Cheung et al. 2017) cells, providing evidence for distinct roles of BET family members. We showed that mutation of a specific CTCF site using genome editing led to loss of both CTCF and BRD2 binding, whereas depletion of BRD2 appeared to have little effect on CTCF occupancy, indicating that CTCF recruits BRD2 to co-bound sites.

CTCF has known roles as an insulator protein by preventing the inappropriate spreading of chromatin states and as an enhancer blocker that inhibits errant pairing of enhancers and promoters (for review, see Phillips and Corces 2009). To test whether BRD2 and CTCF are functionally linked, we mutated a CTCF/BRD2 site that sits between two unrelated genes. One gene, Slc25a37, is driven by an erythroid-specific enhancer, whereas the gene on the other side, Entpd4, is independently regulated (Huang et al. 2016). Deletion of the CTCF/BRD2 site between these two genes led to inappropriate activation of Entpd4, but only under conditions in which the Slc25a37 enhancer was active. Accordingly, the enhancer formed ectopic contacts with the Entpd4 promoter, indicating that CTCF performs a boundary or enhancer-blocking function at this locus. Single-molecule mRNA FISH confirmed these findings by demonstrating that, at the single-cell level, the expression of these two genes becomes increasingly correlated with either deletion of the intervening CTCF/BRD2 cooccupied site or with BRD2 depletion. Conceptually analogous findings were recently reported at another erythroid 
gene locus, in which mutation of CTCF sites at the $\alpha$ globin gene cluster in mice resulted in the formation of new contacts between the $\alpha$-globin enhancer and the promoters of adjacent genes normally protected from its influence (Hanssen et al. 2017).

More recently CTCF has been shown to frequently mark the borders of topologically associating domains (TADs), which separate the genome into distinct regions that appear to limit the space within which chromatin interactions are permitted to form (Dixon et al. 2012; Nora et al. 2012). Prolonged or acute depletion of CTCF leads to increased cross-TAD boundary contacts and varying degrees of reduction in TAD boundary insulation (Zuin et al. 2014; Kubo et al. 2017; Nora et al. 2017). This is consistent with CTCF-dependent and -independent mechanisms of boundary formation. Notably, sustained BRD2 depletion in erythroid cells also led to increased contacts across chromatin domain boundaries, specifically at those boundaries occupied by BRD2 (Hsu et al. 2017), suggesting that BRD2 may potentiate CTCF's ability to maintain domain border integrity. The effects of BRD2 depletion may be less pronounced compared to those observed upon CTCF depletion in other contexts, which might be due to compensatory mechanisms, perhaps mediated by BRD3, or reflect that CTCF likely functions with multiple cofactors to form or reinforce boundaries. It is worth noting that BRD2 depletion did not reduce CTCF or cohesin binding to chromatin (Hsu et al. 2017), suggesting a parallel or downstream function of BRD2 in establishing chromatin contacts.

Our observations indicate that BRD2 participates in CTCF's ability to form chromatin domains - both in a locus-specific fashion by ensuring an appropriate range of enhancer activity and on a genome-wide scale by maintaining the integrity of architectural boundaries. BRD3 also associates with CTCF sites and thus may have similar functions. BRD4 likely regulates chromatin structure through a distinct mechanism, as it does not appear to bind CTCF sites to the same degree. Many questions remain regarding how BRD2 modulates the activity of CTCF, and the mechanisms by which it contributes to boundary formation. In particular, understanding how and under what contexts BRD2 is recruited to CTCF sites may provide valuable insight. Further study of how BRD2 and CTCF interact - and whether the interaction is direct - could allow dissection of BRD2's function through the construction of mutated forms that are unable to bind CTCF sites.

BET proteins can be found at enhancers and promoters where they can be recruited by acetylated transcription factors. For example, the transcription factor GATA1, which binds to numerous enhancers and promoters in erythroid cells, is involved in chromatin looping (Vakoc et al. 2005), is acetylated (Hung et al. 1999), and is associated with BET proteins (Lamonica et al. 2011). However, preliminary experiments showed that treatment with BET inhibitors did not disrupt GATA1-dependent enhancerpromoter contacts at the $\beta$-globin locus (unpublished observation). Whether BET proteins directly contribute to the formation of specific loops at other genes remains to be explored. Finally, similar to CTCF, BET proteins are located at diverse genomic sites including those unrelated to boundaries, raising the question as to what contextual features specify architectural from nonarchitectural functions of BET proteins. Further study of such questions has the potential to shed light on the transcriptional effects of BRD2 depletion, and by extension may lead to better predictions of the transcriptional and biological responses to BET inhibitors.

\section{POTENTIAL MECHANISMS OF BET PROTEINS IN CHROMATIN DOMAIN BOUNDARY FORMATION}

Our recent work identified a functional association between BRD2 and CTCF in the maintenance of chromatin domain boundaries, but how BRD2 exerts boundary function remains unclear. One potential mechanism may be through the formation of loops that physically isolate regions of chromatin from one another. Crystal structures of the first bromodomain of BRD2 showed that it has the potential to form homodimers (Nakamura et al. 2007), suggesting that BRD2 molecules bound at different genomic locations may be able to associate with one another. BET proteins, including BRD2, have an additional conserved domain termed "motif b," which can mediate the formation of heterodimers with BRD3 and BRD4 (GarciaGutierrez et al. 2012). BET proteins' dual bromodomains may also be able to bind to and bring distant regions of the genome into closer proximity. Recent work in Kaposi's sarcoma-associated herpesvirus (KSHV) supports a role, albeit likely indirect, for BET proteins in sustaining looping interactions. Specifically, BRD2 and BRD4 associate with $\mathrm{CTCF} /$ cohesin binding sites in the latent and lytic control regions of the viral genome, and treatment with the BET inhibitor JQ1 activated the lytic cycle transcriptional program and reduced looped viral genomic contacts (Chen et al. 2017). Loop disruption was associated with diminished binding of cohesin, likely explaining the loss of contacts and contrasting with the above-mentioned findings in erythroid cells.

TAD boundaries have been proposed to form through a number of mechanisms. In one model, CTCF complexes at either end of a TAD form a looping interaction that separates the intervening chromatin from surrounding regions (Rao et al. 2014; Rudan and Hadjur 2015; Sanborn et al. 2015; Dekker and Mirny 2016). Others have suggested that intra-TAD interactions also contribute to the boundaries between domains (Giorgetti et al. 2014). As described above, BRD2 may facilitate or stabilize loops involved in either scenario. Additional models of TAD boundary formation hypothesize that such boundaries represent regions of the genome with specific structural requirements (Dixon et al. 2016a). TAD boundaries are enriched for transcription start sites (TSSs) and housekeeping genes, suggesting that they are associated with highly active transcription (Dixon et al. 2012). Such models propose that factors such as nucleosome spacing around TSSs or CTCF sites, which are known to be associated with specific nucleosome spacing parameters 
(Fu et al. 2008), may impose limits on chromatin flexibility that subsequently generate a boundary (Dixon et al. 2016a). It is possible that BRD2 may promote high levels of transcription at certain boundaries. In addition, BRD2 was recently reported to bind the histone variant H2A.Z (Vardabasso et al. 2015; Surface et al. 2016), which is enriched in the nucleosomes arrayed around CTCF sites (Fu et al. 2008), suggesting that it might contribute to structural features of boundary regions.

\section{CONCLUSION}

Members of the BET protein family clearly exert both overlapping and distinct functions that are partly reflected in their genomic localization patterns (Stonestrom et al. 2015). Roles of BET proteins at enhancers and promoters and in gene bodies are well described, but recent reports summarized here further suggest that BRD2, and perhaps BRD3, carry out separate functions at chromatin domain boundaries. BRD2 appears to strengthen boundaries alone or in the context of CTCF by helping to confine long-range chromatin contacts to within domains (Hsu et al. 2017). Although CTCF is required for BRD2 recruitment to their colocalized sites, what tethers BRD2 to boundaries devoid of CTCF is currently unknown. Future studies will need to address whether BRD2 assists looped contacts between boundaries, and whether such contacts are required for boundary activity. Also, assessing whether BET proteins may be sufficient for boundary formation is an important next step. Genome editing to perturb existing boundaries combined with the use of gain-offunction tethering experiments might shed light on these questions. If indeed BET proteins contribute to boundary function in Drosophila as discussed above, whole organismal studies may be within reach. Another unresolved question is why protein association studies of CTCF have not detected BET proteins and, conversely, why assessments of BET-associated protein complexes do not seem to involve CTCF. However, contacts might be indirect or may be stabilized in the context of a permissive chromatin environment. Sub-TADs, or subdomains, are structures that display more variation between cell types (Phillips-Cremins et al. 2013; Dixon et al. 2016b). Given the association of BET proteins with tissue-specific or inducible gene expression programs, one possibility may be that they form similarly "inducible" boundaries that constrain tissue-specific enhancers upon their activation.

Most current BET inhibitors show little specificity for individual BET family members. Although experiments have been performed to attribute the phenotypic consequences of BET inhibition to the impairment of particular BET proteins, interpretation of the results has been limited in part because of the overlapping functions of BET proteins defined in cellular assays and may also be complicated by BRD2's role as a boundary factor. This underscores the need for further studies to understand and predict the consequences of BET inhibition in a given tissue or disease context.

\section{ACKNOWLEDGMENTS}

This work was supported by National Institutes of Health (NIH) grants RO1DK54937, R24DK106766, and U01HL129998A to G.A.B. The Patel Family Scholar Award supported S.C.H.

\section{REFERENCES}

Alekseyenko AA, Walsh EM, Wang X, Grayson AR, Hsi PT, Kharchenko PV, Kuroda MI, French CA. 2015. The oncogenic BRD4-NUT chromatin regulator drives aberrant transcription within large topological domains. Genes Dev 29: $1507-1523$

Alekseyenko AA, Walsh EM, Zee BM, Pakozdi T, Hsi P, Lemieux ME, Dal Cin P, Ince TA, Kharchenko PV, Kuroda MI, et al. 2017. Ectopic protein interactions within BRD4chromatin complexes drive oncogenic megadomain formation in NUT midline carcinoma. Proc Natl Acad Sci 114: E4184E4192.

Anand P, Brown JD, Lin CY, Qi J, Zhang R, Artero PC, Alaiti MA, Bullard J, Alazem K, Margulies KB, et al. 2013. BET bromodomains mediate transcriptional pause release in heart failure. Cell 154: 569-582.

Anders L, Guenther MG, Qi J, Fan ZP, Marineau JJ, Rahl PB, Lovén J, Sigova AA, Smith WB, Lee TI, et al. 2013. Genomewide localization of small molecules. Nat Biotechnol 32: 92 96.

Asangani IA, Dommeti VL, Wang X, Malik R, Cieslik M, Yang R, Escara-Wilke J, Wilder-Romans K, Dhanireddy S, Engelke C, et al. 2015. Therapeutic targeting of BET bromodomain proteins in castration-resistant prostate cancer. Nature 510: 278-282.

Belkina AC, Denis GV. 2012. BET domain co-regulators in obesity, inflammation and cancer. Nat Rev Cancer 12: 465-477.

Berkovits BD, Wolgemuth DJ. 2011. The first bromodomain of the testis-specific double bromodomain protein Brdt is required for chromocenter organization that is modulated by genetic background. Dev Biol 360: 358-368.

Bisgrove DA, Mahmoudi T, Henklein P, Verdin E. 2007. Conserved P-TEFb-interacting domain of BRD4 inhibits HIV transcription. Proc Natl Acad Sci 104: 13690-13695.

Bryant JM, Donahue G, Wang X, Meyer-Ficca M, Luense LJ, Weller AH, Bartolomei MS, Blobel GA, Meyer RG, Garcia BA, et al. 2015. Characterization of BRD4 during mammalian postmeiotic sperm development. Mol Cell Biol 35: 14331448.

Chen H-S, De Leo A, Wang Z, Kerekovic A, Hills R, Lieberman PM. 2017. BET-inhibitors disrupt Rad21-dependent conformational control of KSHV latency. PLoS Pathog 13: e1006100.

Cheung KL, Zhang F, Jaganathan A, Sharma R, Zhang Q, Konuma T, Shen T, Lee J-Y, Ren C, Chen C-H, et al. 2017. Distinct roles of Brd2 and Brd4 in potentiating the transcriptional program for Th17 cell differentiation. Mol Cell 65: 1068-1080.e5.

Dawson MA, Prinjha RK, Dittmann A, Giotopoulos G, Bantscheff M, Chan W-I, Robson SC, Chung C-W, Hopf C, Savitski $\mathrm{MM}$, et al. 2011. Inhibition of BET recruitment to chromatin as an effective treatment for MLL-fusion leukaemia. Nature 478: 529-533.

Dekker J, Mirny L. 2016. The 3D genome as moderator of chromosomal communication. Cell 164: 1110-1121.

Delmore JE, Issa GC, Lemieux ME, Rahl PB, Shi J, Jacobs HM, Kastritis E, Gilpatrick T, Paranal RM, Qi J, et al. 2011. BET bromodomain inhibition as a therapeutic strategy to target cMyc. Cell 146: 904-917.

Denis GV, Vaziri C, Guo N, Faller DV. 2000. RING3 kinase transactivates promoters of cell cycle regulatory genes through E2F. Cell Growth Differ 11: 417-424. 
Devaiah BN, Lewis BA, Cherman N, Hewitt MC, Albrecht BK, Robey PG, Ozato K, Sims RJ, Singer DS. 2012. BRD4 is an atypical kinase that phosphorylates serine2 of the RNA polymerase II carboxy-terminal domain. Proc Natl Acad Sci 109: 6927-6932.

Devaiah BN, Case-Borden C, Gegonne A, Hsu CH, Chen Q, Meerzaman D, Dey A, Ozato K, Singer DS. 2016. BRD4 is a histone acetyltransferase that evicts nucleosomes from chromatin. Nat Struct Mol Biol 23: 540-548.

Dey A, Ellenberg J, Farina A, Coleman AE, Maruyama T, Sciortino S, Lippincott-Schwartz J, Ozato K. 2000. A bromodomain protein, MCAP, associates with mitotic chromosomes and affects $\mathrm{G}_{2}$-to-M transition. Mol Cell Biol 20: 6537-6549.

Dey A, Nishiyama A, Karpova T, McNally J, Ozato K. 2009. Brd4 marks select genes on mitotic chromatin and directs postmitotic transcription. Mol Biol Cell 20: 4899-4909.

Dixon JR, Selvaraj S, Yue F, Kim A, Li Y, Shen Y, Hu M, Liu JS, Ren B. 2012. Topological domains in mammalian genomes identified by analysis of chromatin interactions. Nature $\mathbf{4 8 5}$ : 376-380.

Dixon JR, Gorkin DU, Ren B. 2016a. Chromatin domains: The unit of chromosome organization. Mol Cell 62: 668-680.

Dixon JR, Jung I, Selvaraj S, Shen Y, Antosiewicz-Bourget JE, Lee AY, Ye Z, Kim A, Rajagopal N, Xie W, et al. 2016b. Chromatin architecture reorganization during stem cell differentiation. Nature 518: 331-336.

Filippakopoulos P, Qi J, Picaud S, Shen Y, Smith WB, Fedorov O, Morse EM, Keates T, Hickman TT, Felletar I, et al. 2010. Selective inhibition of BET bromodomains. Nature 468: 1067-1073.

Fu Y, Sinha M, Peterson CL, Weng Z. 2008. The insulator binding protein CTCF positions 20 nucleosomes around its binding sites across the human genome. PLoS Genet 4: e1000138.

Garcia-Gutierrez P, Mundi M, Garcia-Dominguez M. 2012. Association of bromodomain BET proteins with chromatin requires dimerization through the conserved motif B. J Cell Sci 125: $3671-3680$.

Giorgetti L, Galupa R, Nora EP, Piolot T, Lam F, Dekker J, Tiana G, Heard E. 2014. Predictive polymer modeling reveals coupled fluctuations in chromosome conformation and transcription. Cell 157: 950-963.

Hanssen LLP, Kassouf MT, Oudelaar AM, Biggs D, Preece C, Downes DJ, Gosden M, Sharpe JA, Sloane-Stanley JA, Hughes JR, et al. 2017. Tissue-specific CTCF-cohesin-mediated chromatin architecture delimits enhancer interactions and function in vivo. Nat Cell Biol 19: 952-961.

Hsu SC, Gilgenast TG, Bartman CR, Edwards CR, Stonestrom AJ, Huang P, Emerson DJ, Evans P, Werner MT, Keller CA, et al. 2017. The BET protein BRD2 cooperates with CTCF to enforce transcriptional and architectural boundaries. Mol Cell 66: 102-116.e7.

Huang J, Liu X, Li D, Shao Z, Cao H, Zhang Y, Trompouki E, Bowman TV, Zon LI, Yuan G-C, et al. 2016. Dynamic control of enhancer repertoires drives lineage and stage-specific transcription during hematopoiesis. Dev Cell 36: 9-23.

Hung HL, Lau J, Kim AY, Weiss MJ, Blobel GA. 1999. CREBbinding protein acetylates hematopoietic transcription factor GATA-1 at functionally important sites. Mol Cell Biol 19: 3496-3505.

Jang MK, Mochizuki K, Zhou M, Jeong H-S, Brady JN, Ozato K. 2005. The bromodomain protein Brd4 is a positive regulatory component of $\mathrm{P}-\mathrm{TEFb}$ and stimulates RNA polymerase IIdependent transcription. Mol Cell 19: 523-534.

Kanno T, Kanno Y, Siegel RM, Jang MK, Lenardo MJ, Ozato K. 2004. Selective recognition of acetylated histones by bromodomain proteins visualized in living cells. Mol Cell 13: 33-43.

Kellner WA, Van Bortle K, Li L, Ramos E, Takenaka N, Corces VG. 2013. Distinct isoforms of the Drosophila Brd4 homologue are present at enhancers, promoters and insulator sites. Nucleic Acids Res 41: 9274-9283.

Kubo N, Ishii H, Gorkin D, Meitinger F, Xiong X, Fang R, Liu T, Ye Z, Li B, Dixon J, et al. 2017. Preservation of chromatin organization after acute loss of CTCF in mouse embryonic stem cells. bioRxiv doi: 10.1101/118737.

Ladurner AG, Inouye C, Jain R, Tjian R. 2003. Bromodomains mediate an acetyl-histone encoded antisilencing function at heterochromatin boundaries. Mol Cell 11: 365-376.

Lamonica JM, Deng W, Kadauke S, Campbell AE, Gamsjaeger R, Wang H, Cheng Y, Billin AN, Hardison RC, Mackay JP, et al. 2011. Bromodomain protein Brd3 associates with acetylated GATA1 to promote its chromatin occupancy at erythroid target genes. Proc Natl Acad Sci 108: E159-E168.

LeRoy G, Rickards B, Flint SJ. 2008. The double bromodomain proteins $\mathrm{Brd} 2$ and $\mathrm{Brd} 3$ couple histone acetylation to transcription. Mol Cell 30: 51-60.

Nakamura Y, Umehara T, Nakano K, Jang MK, Shirouzu M, Morita S, Uda-Tochio H, Hamana H, Terada T, Adachi N, et al. 2007. Crystal structure of the human BRD2 bromodomain: Insights into dimerization and recognition of acetylated histone H4. J Biol Chem 282: 4193-4201.

Naumova N, Imakaev M, Fudenberg G, Zhan Y, Lajoie BR, Mirny LA, Dekker J. 2013. Organization of the mitotic chromosome. Science 342: 948-953.

Nicodeme E, Jeffrey KL, Schaefer U, Beinke S, Dewell S, Chung C-W, Chandwani R, Marazzi I, Wilson P, Coste H, et al. 2011. Suppression of inflammation by a synthetic histone mimic. Nature 468: 1119-1123.

Nora EP, Lajoie BR, Schulz EG, Giorgetti L, Okamoto I, Servant N, Piolot T, van Berkum NL, Meisig J, Sedat J, et al. 2012. Spatial partitioning of the regulatory landscape of the X-inactivation centre. Nature 485: 381-385.

Nora EP, Goloborodko A, Valton A-L, Gibcus JH, Uebersohn A, Abdennur N, Dekker J, Mirny LA, Bruneau BG. 2017. Targeted degradation of CTCF decouples local insulation of chromosome domains from genomic compartmentalization. Cell 169: 930-933.e22.

Phillips JE, Corces VG. 2009. CTCF: Master weaver of the genome. Cell 137: 1194-1211.

Phillips-Cremins JE, Sauria MEG, Sanyal A, Gerasimova TI, Lajoie BR, Bell JSK, Ong C-T, Hookway TA, Guo C, Sun Y, et al. 2013. Architectural protein subclasses shape 3D organization of genomes during lineage commitment. Cell 153: 1281-1295.

Pivot-Pajot C, Caron C, Govin J, Vion A, Rousseaux S, Khochbin S. 2003. Acetylation-dependent chromatin reorganization by BRDT, a testis-specific bromodomain-containing protein. Mol Cell Biol 23: 5354-5365.

Rahman S, Sowa ME, Ottinger M, Smith JA, Shi Y, Harper JW, Howley PM. 2011. The Brd4 extraterminal domain confers transcription activation independent of pTEFb by recruiting multiple proteins, including NSD3. Mol Cell Biol 31: 26412652.

Rajender S, Avery K, Agarwal A. 2011. Epigenetics, spermatogenesis and male infertility. Mutat Res 727: 62-71.

Rao SSP, Huntley MH, Durand NC, Stamenova EK, Bochkov ID, Robinson JT, Sanborn AL, Machol I, Omer AD, Lander ES, et al. 2014. A 3D map of the human genome at kilobase resolution reveals principles of chromatin looping. Cell 159: $1665-1680$.

Rudan MV, Hadjur S. 2015. Genetic tailors: CTCF and cohesin shape the genome during evolution. Trends Genet 31: 651660.

Sanborn AL, Rao SSP, Huang S-C, Durand NC, Huntley MH, Jewett AI, Bochkov ID, Chinnappan D, Cutkosky A, Li J, et al. 2015. Chromatin extrusion explains key features of loop and domain formation in wild-type and engineered genomes. Proc Natl Acad Sci 112: E6456-E6465.

Schwartz YB, Cavalli G. 2017. Three-dimensional genome organization and function in Drosophila. Genetics 205: $5-24$.

Shang E, Salazar G, Crowley TE, Wang X, Lopez RA, Wang X, Wolgemuth DJ. 2004. Identification of unique, differentiation stage-specific patterns of expression of the bromodomain-containing genes Brd2, Brd3, Brd4, and Brdt in the mouse testis. Gene Expr Patterns 4: 513-519. 


\section{BET PROTEINS IN CHROMATIN STRUCTURE}

Shang E, Nickerson HD, Wen D, Wang X, Wolgemuth DJ. 2007. The first bromodomain of Brdt, a testis-specific member of the BET sub-family of double-bromodomain-containing proteins, is essential for male germ cell differentiation. Development 134: $3507-3515$.

Shen C, Ipsaro JJ, Shi J, Milazzo JP, Wang E, Roe J-S, Suzuki Y, Pappin DJ, Joshua-Tor L, Vakoc CR. 2015. NSD3-short is an adaptor protein that couples BRD4 to the CHD8 chromatin remodeler. Mol Cell 60: 847-859.

Shi J, Vakoc CR. 2014. The mechanisms behind the therapeutic activity of BET bromodomain inhibition. Mol Cell 54: 728 736.

Sinha A, Faller DV, Denis GV. 2005. Bromodomain analysis of Brd2-dependent transcriptional activation of cyclin A. Biochem J 387: 257-269.

Stonestrom AJ, Hsu SC, Jahn KS, Huang P, Keller CA, Giardine BM, Kadauke S, Campbell AE, Evans P, Hardison RC, et al. 2015. Functions of BET proteins in erythroid gene expression. Blood 125: 2825-2834.

Surface LE, Fields PA, Subramanian V, Behmer R, Udeshi N, Peach SE, Carr SA, Jaffe JD, Boyer LA. 2016. H2A.Z.1 monoubiquitylation antagonizes BRD2 to maintain poised chromatin in ESCs. Cell Rep 14: 1142-1155.

Tropberger P, Pott S, Keller C, Kamieniarz-Gdula K, Caron M, Richter F, Li G, Mittler G, Liu ET, Bühler M, et al. 2013. Regulation of transcription through acetylation of H3K122 on the lateral surface of the histone octamer. Cell 152: 859872

Vakoc CR, Letting DL, Gheldof N, Sawado T, Bender MA, Groudine M, Weiss MJ, Dekker J, Blobel GA. 2005. Proximity among distant regulatory elements at the $\beta$-globin locus requires GATA-1 and FOG-1. Mol Cell 17: 453-462.

Vardabasso C, Gaspar-Maia A, Hasson D, Pünzeler S, ValleGarcia D, Straub T, Keilhauer EC, Strub T, Dong J, Panda T, et al. 2015. Histone variant H2A.Z.2 mediates proliferation and drug sensitivity of malignant melanoma. Mol Cell 59: $75-88$.

Wang R, Li Q, Helfer CM, Jiao J, You J. 2012. Bromodomain protein $\mathrm{Brd} 4$ associated with acetylated chromatin is important for maintenance of higher-order chromatin structure. J Biol Chem 287: 10738-10752.

Wu SY, Chiang CM. 2007. The double bromodomain-containing chromatin adaptor Brd4 and transcriptional regulation. J Biol Chem 282: 13141-13145.

Yang Z, Yik JHN, Chen R, He N, Jang MK, Ozato K, Zhou Q. 2005. Recruitment of P-TEFb for stimulation of transcriptional elongation by the bromodomain protein Brd4. Mol Cell 19: 535-545.

Zhao R, Nakamura T, Fu Y, Lazar Z, Spector DL. 2011. Gene bookmarking accelerates the kinetics of post-mitotic transcriptional re-activation. Nat Cell Biol 13: 1295-1304.

Zuber J, Shi J, Wang E, Rappaport AR, Herrmann H, Sison EA, Magoon D, Qi J, Blatt K, Wunderlich M, et al. 2011. RNAi screen identifies Brd4 as a therapeutic target in acute myeloid leukaemia. Nature 478: 524-528.

Zuin J, Dixon JR, van der Reijden MIJA, Ye Z, Kolovos P, Brouwer RWW, van de Corput MPC, van de Werken HJG, Knoch TA, van IJcken WFJ, et al. 2014. Cohesin and CTCF differentially affect chromatin architecture and gene expression in human cells. Proc Natl Acad Sci 111: 996-1001. 


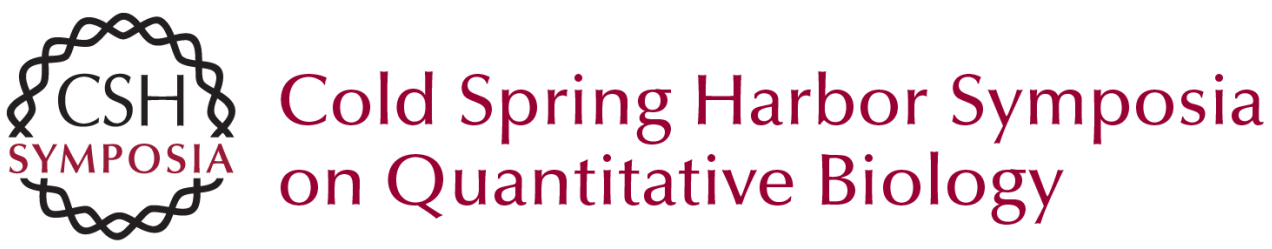

\section{The Role of Bromodomain and Extraterminal Motif (BET) Proteins in Chromatin Structure}

Sarah C. Hsu and Gerd A. Blobel

Cold Spring Harb Symp Quant Biol 2017 82: 37-43 originally published online December 1, 2017 Access the most recent version at doi:10.1101/sqb.2017.82.033829

References This article cites 67 articles, 24 of which can be accessed free at: http://symposium.cshlp.org/content/82/37.full.html\#ref-list-1

Creative This article is distributed under the terms of the

Commons http://creativecommons.org/licenses/by-nc/4.0/, which permits reuse and License redistribution, except for commercial purposes, provided that the original author and source are credited.

Email Alerting Receive free email alerts when new articles cite this article - sign up in Service the box at the top right corner of the article or click here. 